\title{
MOBILIDADE E DESENVOLVIMENTO URBANO: O Plano Diretor Estratégico de São Paulo em Perspectiva
}

\author{
Giulia BrissacTarasconi \\ gbtarasconi@gmail.com \\ Barbara Vallilo Siqueira \\ UFSC - Universidade Federal de Santa Catarina \\ babisv.arq@hotmail.com
}

\section{RESUMO}

A crise de mobilidade nos grandes centros urbanos é considerada como um dos principais problemas atuais. Dentre os avanços jurídicos urbanísticos conquistados pela luta ao direito à cidade, o Plano Diretor Municipal ganha destaque por viabilizar a de definição de estratégias de desenvolvimento urbano associada às estratégias de mobilidade e, nesse sentido, o artigo busca identificar no Plano Diretor Estratégico de São Paulo as estratégias que promovem o direito à cidade como um direito social. A metodologia compreende em pesquisa teórica, apresentação dos avanços jurídicos urbanísticos no Brasil e leitura e a análise do PDE - SP sob à ótica do direito à cidade e da mobilidade urbana. O plano indicou estratégias de ampliação do sistema de transporte público, mas também ganha destaque as ações de combate à ociosidade de imóveis em áreas qualificadas para produção de habitação de interesse social, para adensar áreas bem equipadas da cidade.

Palavras-chave: Direito à cidade; mobilidade; Plano Diretor Estratégico de São Paulo

\section{ABSTRACT}

The crisis of mobility in large urban centers is considered as one of the main problems today. Among the juridical urban advances achieved by the fight to the right to the city, the Municipal Master Plan is highlighted for enabling the definition of urban development strategies associated with mobility strategies and, in this sense, the article seeks to identify in the Strategic Master Plan of São Paulo Strategies that promote the right to city as a social right. The methodology includes theoretical research, presentation of legal urban development in Brazil and reading and analysis of the PDE - SP under the perspective of the right to the city and urban mobility. The plan indicated strategies to expand the public transportation system, but also highlights the actions to combat the idleness of real estate in areas qualified for production of housing of social interest, to densify well-equipped areas of the city.

Keywords: right to city; mobility; Strategic Master Plan of São Paulo 


\section{INTRODUÇÃO}

No Brasil, o intenso processo de expansão dos grandes centros urbanos, impulsionado pela política desenvolvimentista do governo Vargas, marcou o período compreendido entre a década de 1940 e 1960 pelo seu intenso fluxo migratório rural-urbano em que as cidades foram ocupadas seguindo uma lógica de distribuição desigual do território, estabelecendo áreas com diferentes condições de urbanidade e mobilidade, pois o provimento de infraestrutura, o acesso às redes de equipamentos e serviços públicos, as áreas com maior oferta de empregos, dentre outros, não foram distribuídos de forma equitativa nos diferentes setores das cidades.

Dentre os problemas provocados por esse acelerado processo de urbanização, a chamada crise de mobilidade desses grandes centros metropolitanos é considerada como um dos principais problemas atuais. A base dessa crise pode ser associada não apenas pelo crescimento desordenado no período citado anteriormente, mas também pela falta de uma política de uso do solo integrada à política de mobilidade e, por isso, esta atualmente nos debates sobre os modelos de apropriação do espaço urbano, que tem construído cidades cada vez mais insustentáveis (NAKANO, 2015; SCARINGELLA, 2001).

A partir da aprovação do Estatuto da Cidade pela Lei Federal 10.257 em 2001, que regulamentou dos Artigos 182 e 183 do capítulo sobre a "Política Urbana" da Constituição Federal de 1988, o Brasil iniciou uma nova ordem jurídico-urbanística em que seus municípios com população superior a 20 mil habitantes passaram a ser obrigados a elaborar um Plano Diretor Municipal gerando uma expectativa positiva de que cada município poderia introduzir instrumentos urbanísticos que viabilizam a ampliação do acesso a terra urbanizada e do direito à cidade (MARICATO, 2001; ROLNIK, et al, 2011, NAKANO, 2015).

No entanto, grande parte dos planos diretores pós Estatuto da Cidade abordam suas ações de maneira dissociada entre os principais problemas urbanos, dentre eles, o da mobilidade. A superação da falta de conexão entre as políticas públicas de uso do solo e políticas públicas de mobilidade passam por uma nova perspectiva a partir da recente aprovação da Lei Federal da Mobilidade Sustentável (Lei Federal 12.587/2012), pois propõe uma articulação entre os planos diretores e os planos de mobilidade se seus instrumentos forem autoaplicáveis na gestão do solo e associados com os sistemas de transporte (NAKANO, 2015).

Considerando os vínculos existentes entre mobilidade e desenvolvimento urbano, o presente artigo tem como objetivo investigar as formas de incorporação dessas vertentes tendo como estudo de caso o atual Plano Diretor Estratégico de São Paulo aprovado pela Lei no 16.050 em 2014, para tecer algumas considerações sobre como tem sido tratado esses temas e quais são as perspectivas no âmbito do ordenamento territorial.

Diante das perspectivas traçadas e do objetivo exposto, acredita-se que articular mobilidade e desenvolvimento urbano em políticas públicas urbanas poderá ampliar o direito da população à cidade quando integradas às diretrizes de transporte, habitação, emprego e equipamentos sociais.

Para realização do presente trabalho, os procedimentos serão estruturados em três etapas que consistem nas seguintes abordagens: Abordagem Temática, Abordagem Jurídica Urbanística e Abordagem DescritivoAnalítica.

A Abordagem Exploratória é pautada no estudo de um conjunto de temas que tragam subsídios para a consolidação dos conceitos relacionados ao trabalho para melhor compreensão da problemática apresentada, no que diz respeito à mobilidade e ao direito à cidade.

A Abordagem Jurídica Urbanística tem como objetivo apresentar os avanços conquistados pela luta do direito à cidade em âmbito federal e sua aplicação na esfera municipal sob a ótica do desenvolvimento urbano associado às estratégias de mobilidade urbana.

A Abordagem Descritivo-Analítica terá como propósito contrapor a discussão teórica e articular a leitura do Plano Diretor do Município de São Paulo como objeto empírico, para analisar como os Eixos de Estruturação da Transformação Urbana têm em suas proposições de mobilidade articular-se ao desenvolvimento urbano e na ampliação do direito da população à cidade. 
Dessa forma, o presente artigo busca discutir as questões da crise de mobilidade urbana e apresentar as perspectivas a partir dos avanços jurídicos urbanísticos conquistados pela luta do direito à cidade, tendo como objeto de estudo o Plano Diretor Estratégico de São Paulo que ganhou destaque por definir estratégias de desenvolvimento com foco na mobilidade urbana.

\section{MOBILIDADE E O DIREITO À CIDADE}

O deslocamento no espaço urbano com boas condições de acessibilidade, conforto e segurança é uma das principais articulações que garantem aos indivíduos a possibilidade de acesso à cidade, garantindo aos cidadãos a sensação de pertencimento, além de promover a função social da cidade. Portanto, a mobilidade urbana é considerada como um dos assuntos mais relevantes de estudos das cidades e que tem adquirido uma crescente visibilidade, excepcionalmente nas cidades latino americanas em que suas deficiências dos meios de transporte tem reforçado o padrão de segregação socioespacial que afeta mais diretamente a população de menor renda (VIGNOLI, 2008).

Com o automóvel, o modelo de cidade deixou de seguir a lógica da proximidade física e a expansão das cidades, como cita Balbim (2015, p. 38) passa a ser "fruto de abundância fundiária criada pela métrica automobilística" e os deslocamentos ganharam destaque no cotidiano deixando de lado a necessidade de concentração de várias atividades em um único lugar, além de desconsiderar as relações espaciais entre trabalho e moradia.

Paralelamente, os grandes centros urbanos no Brasil são caracterizados por processos de periferização, expressão da produção das desigualdades socioespaciais, seja por espaços periféricos homogêneos, seja por espaços periféricos pautados nas precariedades urbanísticas. Kowarick (1979) inclusive considera que a constituição das metrópoles brasileiras foi pautada na desigual distribuição dos serviços públicos, com destaque para os sistemas de transporte coletivo. Para Sabatini e Sierralta (2006), mesmo que essa má distribuição afete de maneira mais direta a população de menor renda, problemas urbanos como congestionamento e a falta de acessibilidade acabam por sua vez, interferindo na vida urbana de todos os grupos sociais. Complementarmente, afirmam que o reconhecimento dos efeitos provocados pelos padrões de segregação socioespacial é o que faz desse fenômeno um importante objeto de investigação.

Em decorrência dos problemas provocados pelo acelerado processo de urbanização, o baixo padrão de mobilidade, especialmente da população de menor renda que geralmente estão inseridos em áreas distantes e precárias da cidade, têm provocado um modo de vida pouco qualificado e de pouco acesso à cidade. Essa problemática urbana tem sido bastante discutida e o trabalho de Negri (2008) reconhece que:

Morar num bairro periférico de baixa renda hoje significa muito mais do que apenas ser segregado, significa ter oportunidades desiguais em nível social, econômico, educacional, renda, cultural. Isto quer dizer que um morador de um bairro periférico pobre tem condições mínimas de melhorar socialmente ou economicamente. (NEGRI, 2008, p. 136)

Balbim (2015) ao tratar da importância da abordagem sistêmica sobre as questões de mobilidade, ressalta que esse termo é mais recente e surgiu para jogar luz para as novas transformações sociais pelos quais os termos circulação, trânsito ou transporte não abordavam. Acredita que a mobilidade pode ser entendida também como uma prática de inserção social, pois, da mesma forma que ela contribui com a inserção dos cidadãos no mercado de trabalho, na vida social e cultura, quando não aplicada corretamente, acarreta em exclusão social da população menos favorecida.

Ao abordar o tema da mobilidade e sua interação no desenvolvimento urbano Barbosa $(2015$, p. 48$)$ reforça a existência de uma "perversa combinação de distâncias físicas e sociais que se acumulam como desigualdade social de acesso às oportunidades de trabalho, aos bens culturais, aos serviços de saúde, à educação escolar e ao lazer cultural" e tais aspectos confirmam a desigual distribuição de direitos, expressa também pela fragilidade nos sistema de mobilidade.

Nessa mesma linha de argumentação, Cardoso e Matos (2007) tratam da relação entre acessibilidade urbana e exclusão social e sugerem que a mobilidade nas cidades deve ser tratada como uma prática socioespacial, dada a relação entre uso do solo e transporte como um importante indicativo da exclusão ou inclusão social. Nesse sentido, destaca a importância da discussão da noção de mobilidade nas ações e definições de políticas públicas urbanas decorrentes da importância de definir ações também nos seus 
fluxos e não apenas nos seus fixos. Em sua obra O Direito à Cidade, Lefébvre (1969) já havia exposto que o movimento de transitar estava se tornando cada mais vez importante que o próprio habitar.

Como já mencionado anteriormente, a deficiência de mobilidade urbana agrava a segregação social (VIGNOLI, 2008) que, por consequência dificulta o acesso da população a benfeitorias urbanas privando o direito à cidade da população mais pobre. Para tentar entender as consequências desse aspecto, Miller (2007), trabalha com o conceito "friction of distance", que busca um entendimento mais aprimorado da percepção do tempo necessário para percorrer determinadas viagens baseado no alto custo do transporte público e privado, pouca oferta de rotas e frequência de ônibus, e má integração entre os veículos do mesmo tipo de transporte e de diferentes modais, falta de estrutura para pedestres, pouca sinalização (Lucas et al., 2001) e baixos índices de segurança. (Hodgson and Turner, 2003)

Pessoas em desvantagens econômicas e sociais, que são segregadas espacialmente são afetadas pelo "friction of distance" aumentando ainda mais a noção do alto tempo gasto que essa população sofre em seus deslocamentos. Por consequência, preferem realizar suas tarefas nos arredores de seu local de moradia (GREEN, OWEN, 2006; MILLER 2007). Importante destacar que o resultado desse isolamento aumenta ainda mais a falta de interações sociais entre diferentes classes econômicas.

O problema da exclusão social relacionada a mobilidade é um fenômeno dinâmico visto que muda de acordo com a fase da vida, com o tempo e com o espaço geográfico, espacial, demográfico e cultural que o indivíduo se encontra. A exclusão relacionada ao transporte é também relativa ao nível de mobilidade que uma pessoa precisa perante as normas sociais da sociedade em que está inserida. Quanto mais móvel é a sociedade, mais mobilidade uma pessoa precisa para se sentir socialmente incluída. (LUCAS, 2013).

Diante desse contexto, o desafio do planejamento urbano é de mitigar os efeitos negativos da expansão física desenfreada que o carro proporcionou. Para isso as ações de mobilidade urbana devem estar associadas à outros temas da cidade visto que políticas públicas setorizadas não são eficientes no planejamento das cidades pois, pensar os usos nas cidades é de suma importância, mas deve-se também garantir de maneira equilibradas boas condições de acesso às benfeitorias e aos equipamentos urbanos, ou seja, aquilo que a cidade oferece. (BARBOSA, 2015) Nesse sentido, Balbim (2015) destaca a importância de inserir novos meanismos de transformação urbana a partir das questões de mobilidade que poderão alterar os padrões urbanísticos segregados e fragmentados das cidades.

O trabalho de Vasconcellos (2015), reforça o quão importante que as decisões das políticas públicas de mobilidade urbana sejam definidas conjuntamente com a política de uso e ocupação do solo no intuito de evitar a ampliação da segregação socioespacial das camadas de menor renda que, para Negri (2008), uma vez consolidada, apresenta chances desiguais de se ascender socialmente perante a diferença de acessos à infraestrutura, educação, e oferta de emprego. Assim, as políticas públicas urbanas devem repensar suas estratégias e suas ações no intuito, inclusive, de mitigar o isolamento e o frágil padrão de deslocamento já existente para alguns grupos sociais, proporcionando a partir de uma acessibilidade urbana mais igualitária, melhor acesso ao trabalho e aos serviços públicos e, consequentemente, uma maior inclusão social.

\section{POLÍTICAS PÚBLICAS E DESENVOLVIMENTO URBANO}

Como resposta à precariedade dos direitos humanos essenciais, alguns grupos, predominantemente de países subdesenvolvidos, começaram a buscar mudanças no modo de governar, reivindicando a democratização política e melhorias no planejamento da cidade. O Movimento Nacional pela Reforma Urbana surgiu em 1958, consolidando a luta pelo direito à cidade no Brasil com o intuito de discutir o papel das políticas públicas urbanas no sentido de ampliar e melhorar as condições de vida da população e também garantir a interação entre as famílias de diferentes classes sociais.

Umas das conquistas do Movimento resultou na implementação de dois artigos da Constituição Federal de 1988 (182 e 183) sobre política urbana, que foram regulamentados apenas com a aprovação do Estatuto da Cidade pela Lei Federal 10.257 em 2001. O Estatuto tem como princípio fundante a função social da cidade e trata a gestão das cidades de forma democrática como um de seus pilares fundamentais, prevendo a participação popular no processo de desenvolvimento a partir de debates com a população, além de disponibilizar uma série de instrumentos para combater especulação fundiária e promover um acesso à cidade de forma mais equilibrada. Com essas conquistas, o Brasil se tornou referência no cenário de 
política urbana, principalmente por inserir o direito à cidade nos fóruns internacionais urbanos (SAULE JR, 2005).

Apesar dos avanços conquistados sociais pelo Movimento Nacional pela Reforma Urbana de ordem jurídica urbanística, sua aplicabilidade tem sido precária e ineficiente. De acordo com Maricato (2010), o Estatuto da Cidade vêm apresentando dificuldades para aplicar os novos conceitos devido a repressão de parte da sociedade que se posiciona contra a implementação da função social da propriedade e da cidade visto a força do capital imobiliário na produção das cidades. A não efetivação ou a baixa implementação dos instrumentos do Estatuto da Cidade para proporcionar um desenvolvimento urbano mais igualitário impede a promoção do uso da propriedade urbana com ênfase nos interesses dos cidadãos e um ordenamento territorial que considere o desenvolvimento das funções sociais da cidade e da propriedade urbana.

No entanto, além da criação do Ministério das Cidades, outras ações também foram essenciais para o avanço jurídico urbanístico para tratar o novo paradigma da mobilidade urbana no país. À exemplo do Estatuto da Cidade que, em 2001, além de lançar diretrizes de política urbana, exigiu também a criação de Plano Diretor de Transporte e Mobilidade - PlanMob, para as cidades com população superior à 500 mil habitantes, este plano deve estar inserido no plano diretor municipal no intuito de integrar às questões de mobilidade aos outros setor do planejamento das cidades. (BRASIL 2005).

Caldeira (2000) afirma que a segregação, espacial ou social, é um dos fenômenos mais importantes presente nas cidades brasileiras, pois a organização do território urbano se dá a partir dos diferentes padrões sociais e da separação de classes. Ao abordar os padrões de segregação em São Paulo, Torres et al (2003), acreditam que a segregação socioespacial é um fenômeno que pode tanto ser produzido como mitigado por ações governamentais e acredita que a implementação de políticas espaciais associada à políticas sociais, seja uma forma eficiente de garantir a mitigação dos aspectos desiguais presentes no espaço urbano. No sentido de mitigar o fenômeno da segregação, as políticas governamentais de interação social tem o intuito de promover uma maior relação entre os diferentes grupos sociais, e as políticas governamentais de interação espacial visa melhorar as condições das áreas mais precárias da cidade, promovendo uma qualidade espacial semelhante das áreas habitadas pela população de mais alta renda. Para os mesmo autores, as políticas de regulamentação urbana, assim como os investimentos em infraestrutura nos setores da cidade ocupados pela população mais pobre são classificadas como políticas relativas ao espaço. Cabe ressaltar que as políticas de regulação urbana podem inserir os processos de mobilidade de forma que operem em direção contrária aos padrões de segregação. Já o conjunto de políticas públicas sociais referentes à saúde, educação, lazer, cultura, esportes e assistência social também são capazes de transformar o espaço na medida em que sua inserção define as condições de acesso da população à cidade, diminuindo as distâncias sociais entre a população mais pobre e a população de classes mais abastadas.

Ao abordar a produção do espaço urbano, Corrêa (1995) destaca que a atuação do Estado na organização da cidade tem sido complexa tanto no tempo como no espaço. No entanto, para Maricato (2015) o direito à cidade poderá ser garantido muito mais pelas lutas sociais do que pelas normas legais da política urbana.

\section{A CIDADE DE SÃO PAULO EM PERSPECTIVA}

A cidade de São Paulo, situada na região sudeste do Brasil, teve seu ápice de expansão e crescimento populacional marcado na década de 1950, pois passou de 2 milhões de habitante para 3,5 milhões decorrente da expansão do setor industrial. Visto que a população acompanha a oferta de emprego e a cidade de São Paulo é o principal pólo econômico do país, atingiu seus 10 milhões de habitantes no ano de 2000. Devido o seu crescimento populacional e seu processo de conurbação, passou a ser considerada como Metrópole conforme ilustra a Figura 1, que compreende o município de São Paulo e os municípios que conformam a Região Metropolitana. 


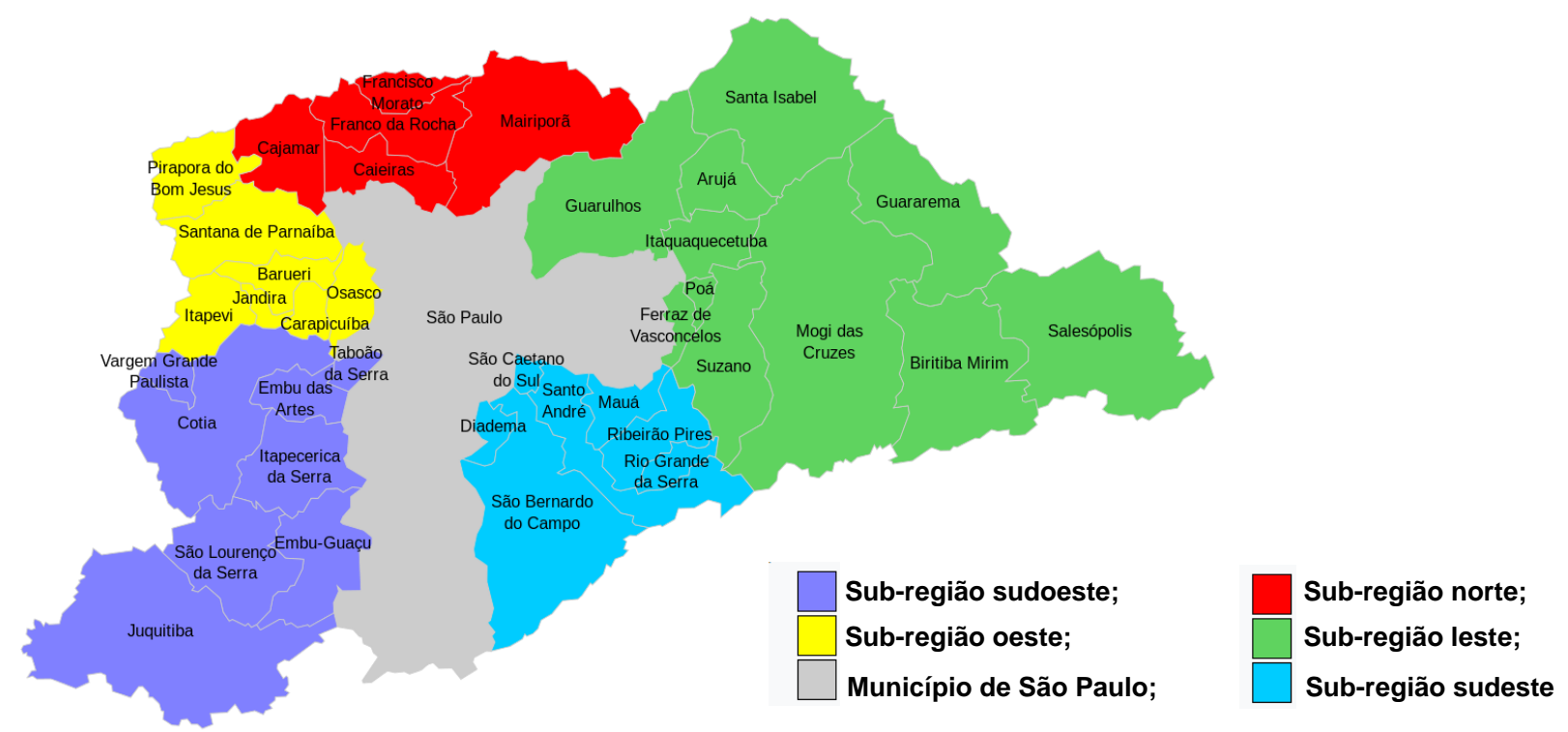

Figura 1 - Região metropolitana de São Paulo (WIKIPEDIA, 2011)

A região marcada em azul claro no mapa abaixo compreende o ABCD paulista, conjunto de cidades industriais anexas a São Paulo que geram um grande fluxo de viagens rodoviárias e ferroviárias para a capital e é responsável por boa parte da economia da metrópole.

São Paulo é uma cidade contemporânea em que a segregação socioespacial não é mais traduzida pela dicotomia centro-periferia, estudada pela Escola de Chicago no início do século XX. No Brasil, a fragmentação espacial estabelecida pela relação centro rico e periferia pobre, baseada no entendimento de setorizações socioespaciais distintas, já foram alteradas nos últimos anos. Assim mais recentemente, a lógica que contrapunha áreas centrais às periféricas, que traduziu determinados períodos da urbanização brasileira, já não traduz os aspecto locacionais da segregação socioespacial, pois com o aumento da violência urbana, novos produtos imobiliários, baseados na ampliação da segurança e da proteção familiar e patrimonial, têm se intensificado a inserção de novos segmentos sociais também nas áreas periféricas (SILVA et al, 2014)

Assim a segregação socioespacial da região metropolitana possui duas realidades: assentamentos precários, distantes e carentes de infraestrutura e condomínios residenciais fechados e luxuosos acessíveis apenas por automóveis particulares, que Caldeira (2000, p. 258) classifica como "enclaves fortificados", destinados para população de média e alta renda.

Segundo Maricato (2015) o centro de São Paulo é a região de maior mobilidade da metrópole e é considerada uma região privilegiada em detrimento de outras em relação ao abastecimento de transporte público e a concentração de ofertas de empregos. Portanto, considerando que a maior parte dos deslocamentos urbanos ocorre para fins de trabalho e moradia, podemos afirmar que a localização dos empregos referentes aos locais de moradias se torna pauta de extrema importância para compreender a articulação da cidade e seu desenvolvimento social e econômico. A Figura 2 ilustra a perversa combinação das distâncias físicas entre oportunidade e vulnerabilidade, pois identifica que a população vulnerável está concentrada nas bordas precárias da cidade e a concentração da oferta de emprego está situado na região central, confirmando a desigual distribuição das oportunidades. 


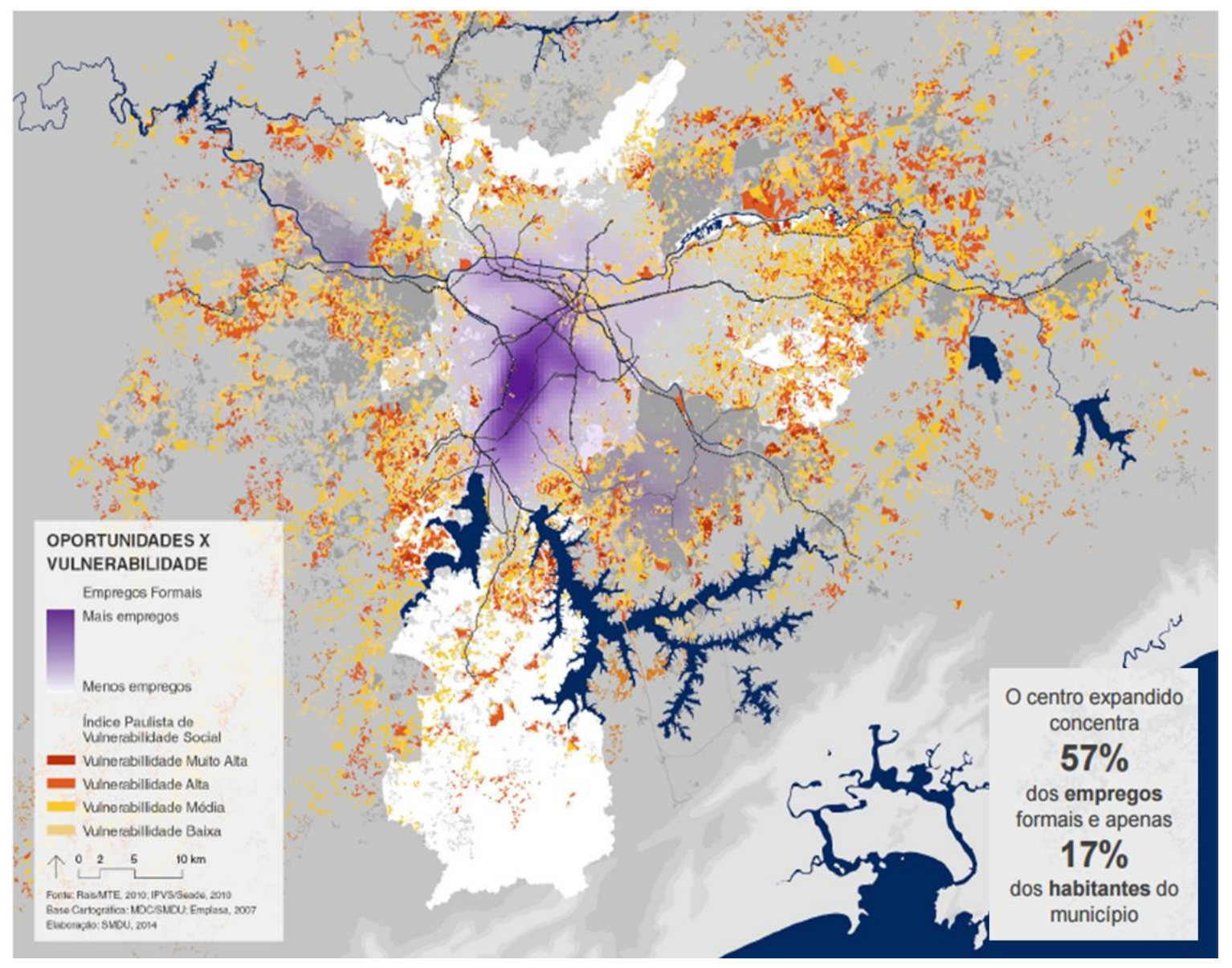

O número de viagens para centro o expandido, onde concentra $57 \%$ do total de ofertas de empregos, gera a superlotação do sistema viário e do transporte coletivo, influenciando na diminuição do acesso às oportunidades e à cidade. Assim, torna-se uma exigência social a ampliação do frágil sistema de mobilidade que afeta os moradores de baixa renda que se inserem em áreas distantes de oportunidades como a região Leste, que se constitui basicamente por famílias de baixa renda, possui poucas indústrias e pouca oferta de emprego, e é alimentada por apenas uma linha de metrô e por um serviço ferroviário extremamente precário. Portanto, é considerada a região da cidade que possui menores condições de acessar as benfeitorias que a cidade oferece, mesmo sendo a que socialmente mais necessita de serviços públicos urbanos de mobilidade.

Conforme já mencionado, São Paulo possui em sua periferia zonas habitadas exclusivamente pela população mais pobre e outras habitadas exclusivamente por pessoas com grande concentração de capital. O que distingue uma área periférica da outra é o "friction of distance" aplicado sobre a localização geográfica em que se insere, fazendo com que uma viagem mais longa ou de igual distância dos condomínios luxuosos para as benfeitorias urbanas seja menos custosa em relação a custo, tempo, energia, em relação a maioria das viagens das regiões de habitações de baixa renda para chegar até o seu local de trabalho.

Através das pesquisas de Origem e Destino realizadas pela Companhia do Metropolitano de São Paulo METRÔ é possível compreender melhor as necessidades de deslocamento moradiatrabalho/lazer/estudos/serviços de cada região da cidade. Essas pesquisas demonstram que o fluxo moradia-trabalho é o mais significativo dentre as famílias pobres devido ao maior número de trabalhadores dentro da família. Além do maior fluxo, esses trabalhadores gastam mais tempo no deslocamento, o que reflete na saúde dos indivíduos por conta das reduções de horas de sono, estresse e restrições de tempo de lazer. 


\section{o plano diRetor de são paulo e suas perspectivas de desenVolvimento e MOBILIDADE URBANA}

O Plano Diretor Estratégico de São Paulo - PDE-SP de 2014, aprovado pela Lei Municipal de no 16.050/2014, principal instrumento de política urbana municipal vigente, foi elaborado pela Secretaria Municipal de Desenvolvimento Urbano - SMDU-SP, juntamente com a sociedade civil a fim de suceder o plano que definiu em 2012, o prazo final para concretização de suas diretrizes. Contou com um processo participativo intenso, em um total de 60 audiências públicas e 25 mil participantes. O plano é apresentado em uma linguagem de fácil compreensão através de um livro ilustrado para que, com o conhecimento e o auxílio da população possa ser possível concluir com sucesso sua total implementação até o ano de 2030 , conforme estipulado em suas metas.

A mobilidade urbana é o tema central no PDE-SP pois define um conjunto de estratégias associadas ao direito à cidade, sendo esse o enfoque do presente artigo. A primeira dessas estratégias é a ampliação do sistema de transporte público no intuito de favorecer o acesso aos equipamentos e as benfeitorias urbanas que a cidade oferece de forma mais igualitária e pode contribuir para inverter o atual modelo de transporte que prioriza o modelo motorizado e individual, como ilustra a Figura 3.

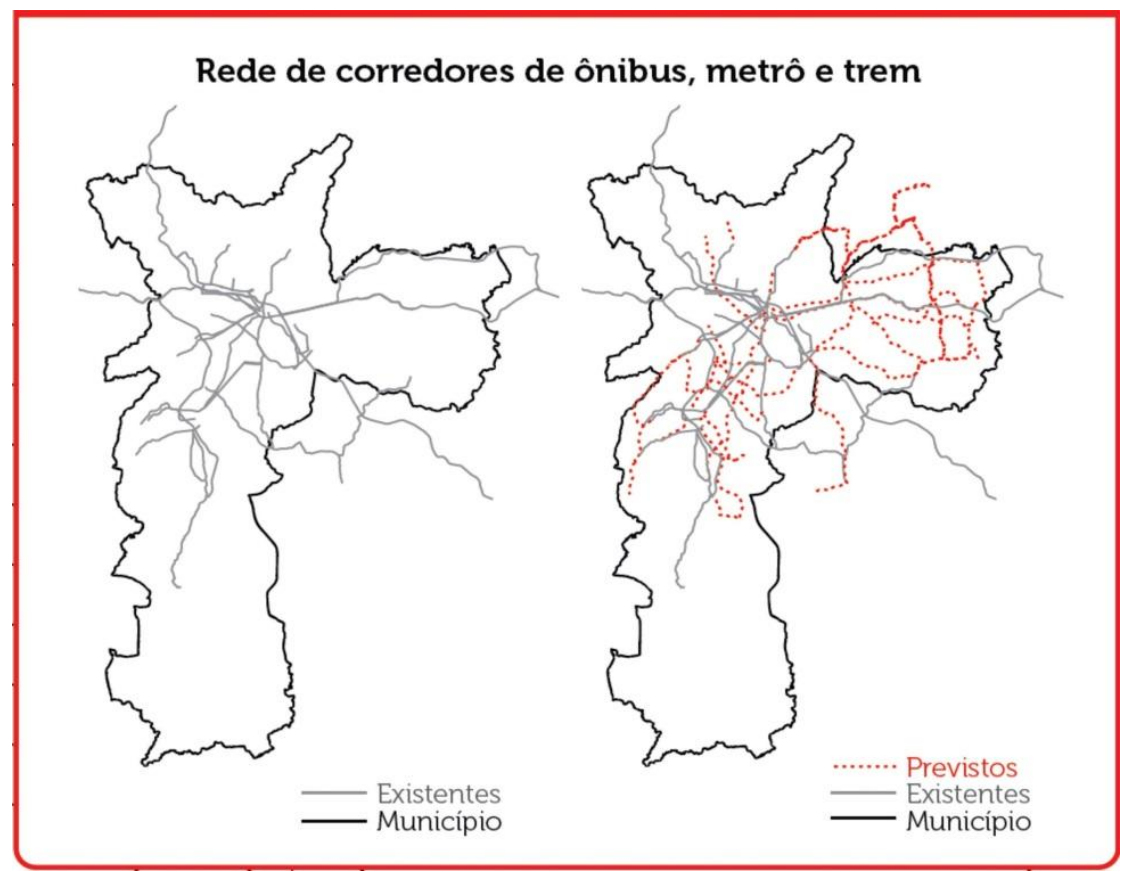

Cabe destacar que a ampliação do sistema de transporte público abrange os corredores de ônibus, metrô e trem e sua ampliação destaca-se na região Leste da cidade conforme a Figura 3, que é caracterizada como já foi citado, pela concentração de famílias de menor renda e pela baixa oferta de emprego. Portanto, essa primeira estratégia visa atender as necessidades específicas da população moradora desse setor que é o de vencer as barreiras sociais decorrente da segregação espacial e estabelecer uma maior relação com os espaços qualificados na cidade de São Paulo, a partir da ampliação de suas condições de mobilidade.

As boas condições para deslocamento a pé e de bicicleta também estimulam o uso do transporte público e, portanto, a ampliação de calçadas com desenho e dimensões mais adequados, além de estimular a caminhada, também contribui para que os paulistanos possam aderir o uso de transporte público. Diante disso, o plano também prevê a implantação de ciclovias, ciclofaixas, ciclorrotas e bicicletários para valorizar o deslocamento de bicicleta e dar condições de circulação para a utilização deste modal não motorizado. Apesar de muita resistência, a cidade de São Paulo já teve um ganho positivo por essa intervenção que já foi iniciada como mostra a Figura 4, 56 e 7 e já apresenta reflexos no tempo diário dos deslocamentos entre trabalho e moradia de parte da população paulistana. 


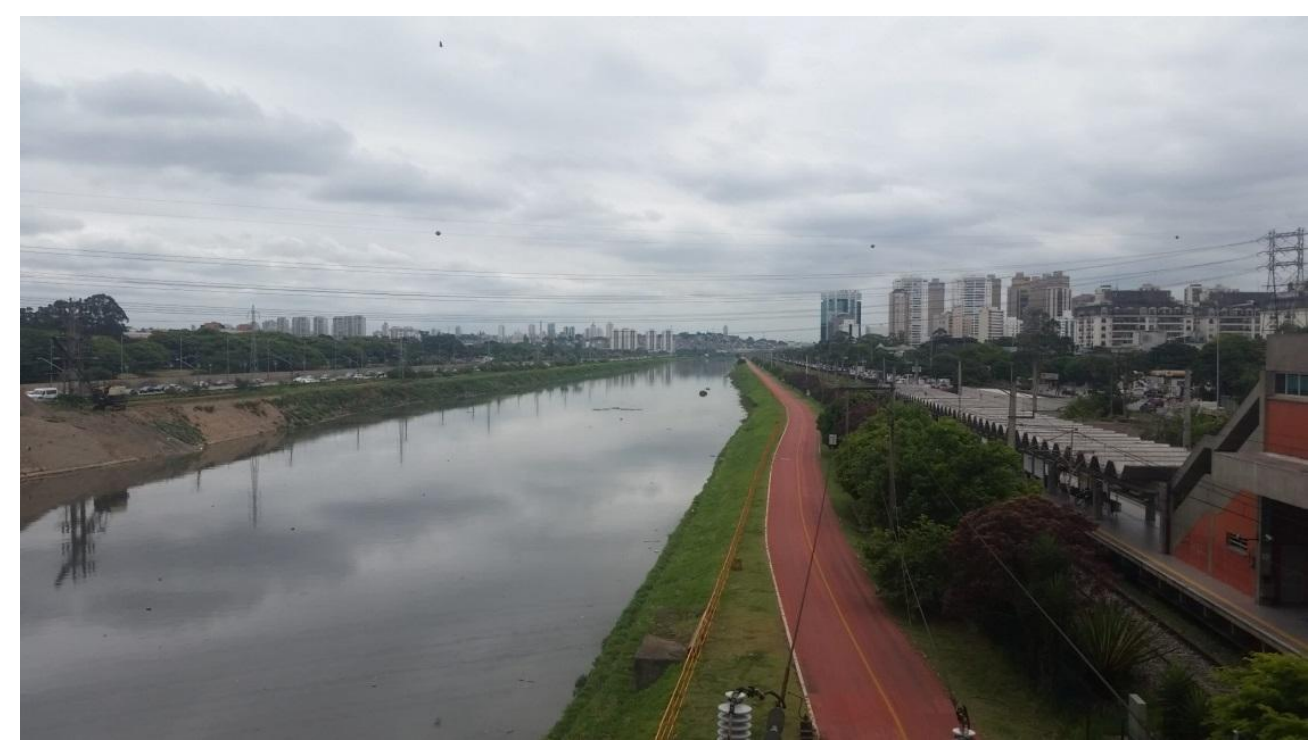

Figura 4: Ciclovia implantada nas margens do Rio Tietê.

Das autoras, 2016.
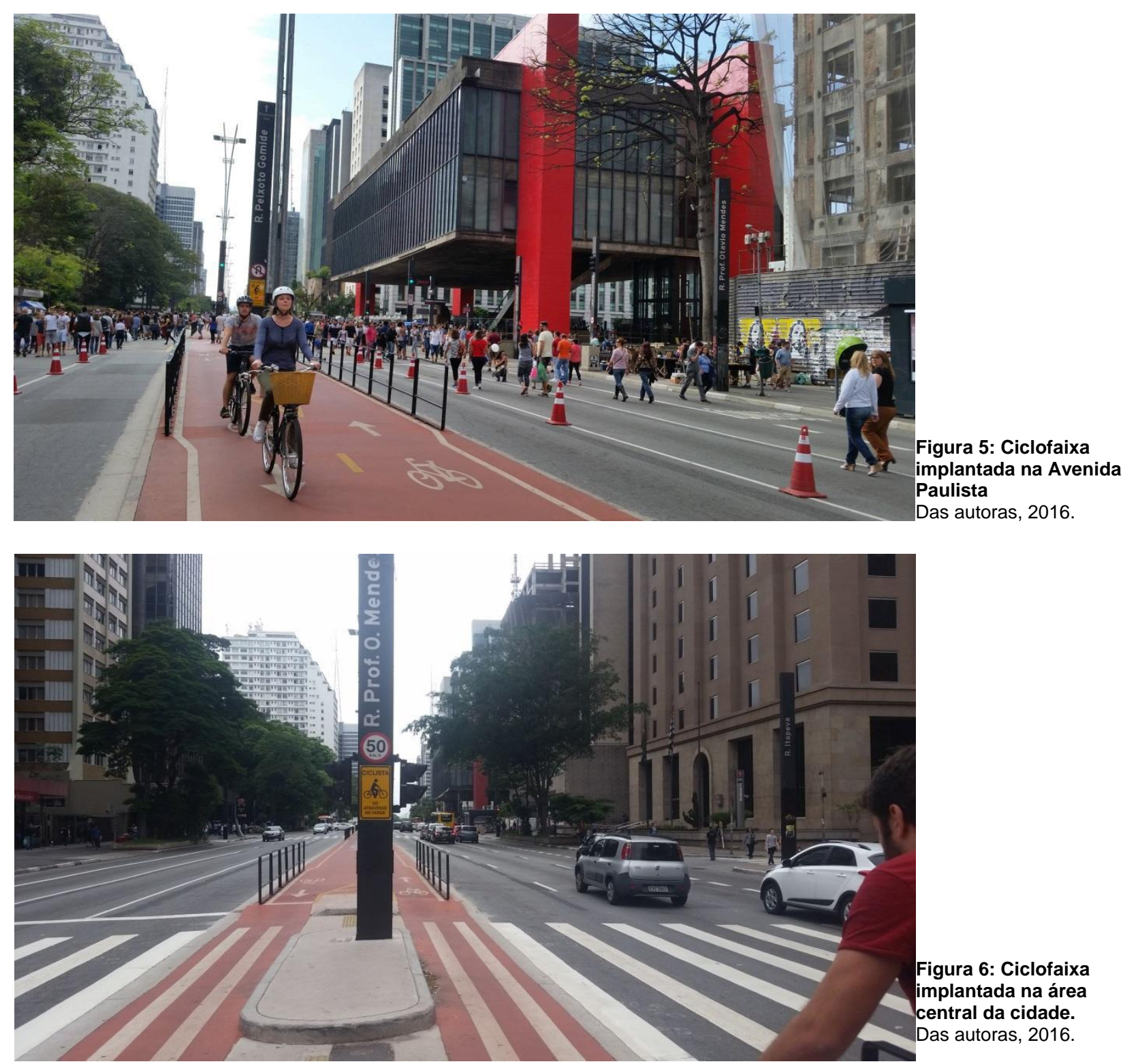


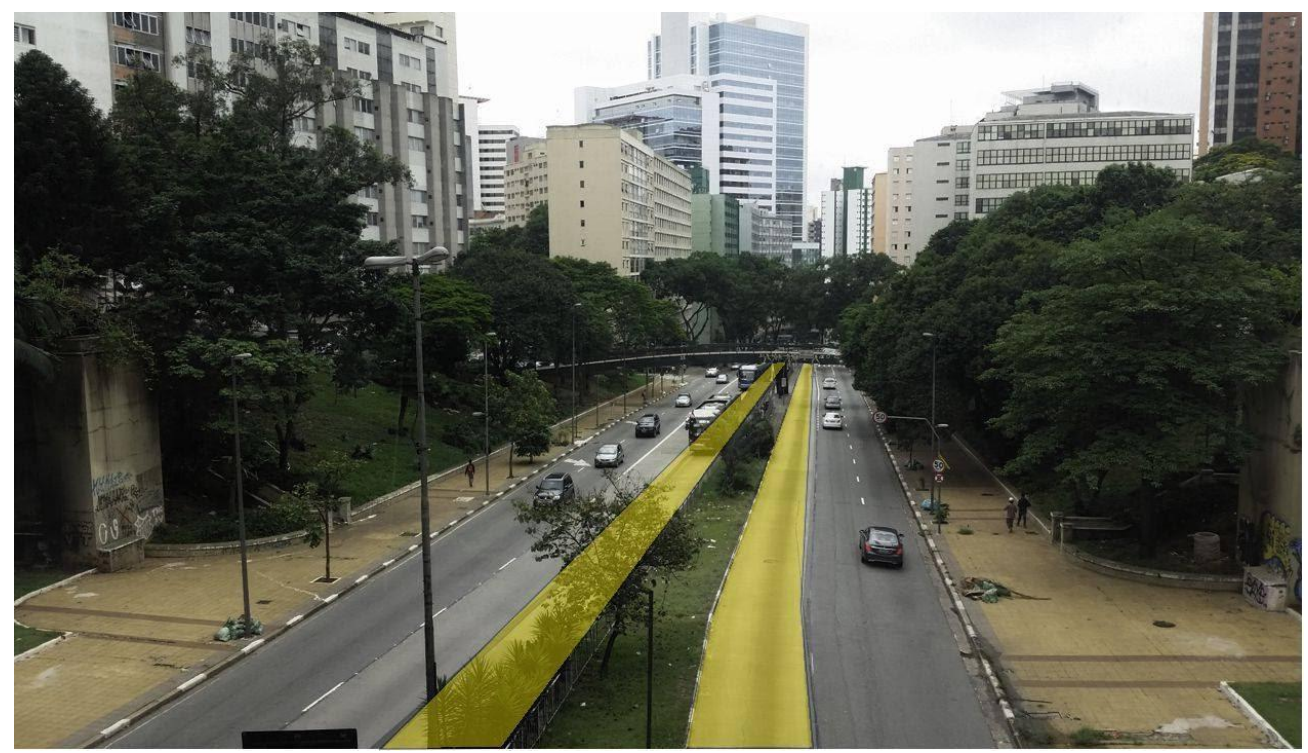

Figura 7 - Corredores exclusivos de ônibus

Das autoras, 2016.

Ganha destaque dentre as estratégias, a definição do Coeficiente de Aproveitamento igual a 1 para toda a cidade, o que significa que para todo o território da cidade de São Paulo, a área máxima para construção sem taxas adicionais é igual a área do terreno em que a obra será realizada. No entanto, caso desejável a construção de uma área acima da área acima da permitida, se viabiliza pelo instrumento da Outorga Onerosa. Em outras palavras, ampliar a possibilidade de construir a partir do pagamento de uma taxa até atingir o coeficiente máximo estipulado em cada zona do território, socializando os ganhos da produção da cidade com os demais cidadãos. Assim, o potencial construtivo adicional pertence a todos os cidadãos e, portanto, os recursos adquiridos devem ser revertidos a todos. A captação de recursos da produção privada da cidade mediante a Outorga Onerosa visa o investimento em benfeitorias urbanas, que são repassados para o Fundo de Desenvolvimento Urbano - FUNDURB que determinará a destinação de investimento com dinheiro provenientes da arrecadação.

O artigo 240 do PDE vigente estipula que o FUNDURB destine $30 \%$ de sua arrecadação para a implantação de transporte público coletivo, de sistema cicloviário e de circulação de pedestre, garantindo ampliação e um contínuo investimento nos recursos destinados à mobilidade.

A segunda estratégia refere-se aos incentivos de aumento populacional nas proximidades do sistema de transporte público através da delimitação de Eixos de Estruturação da Transformação Urbana com o intuito de reduzir a necessidades de grandes deslocamentos. Os Eixos de Estruturação da Transformação Urbana, como mostra a Figura 8, definem o uso de instrumentos para promover um maior adensamento habitacional e construtivo ao longo destes eixos para potencializar o aproveitamento do solo urbano ao longo da rede de transporte coletivo e articular o desenvolvimento urbano com a mobilidade, na tentativa de reverter o modelo de estrutura urbana existente para ampliar o direito à cidade, distribuindo de forma mais equilibrada a moradia e o emprego, já que estes eixos são definidos em áreas com grande oferta de trabalho. 


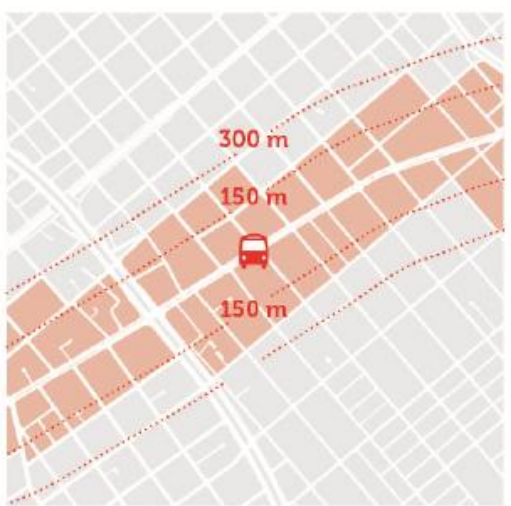

-..- 9 = Eixo davia

Corredor de ónibus

Veículos Leves sobre Pneus (VLP) Em vias não elevadas

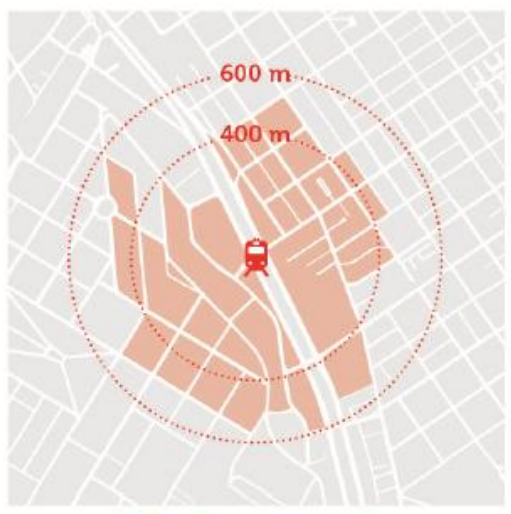

$$
\text { - 頁 = Acesso às estaçóes }
$$

Trem

Monotrilho

Veículos Leves sobre Trilhos (VLT)

Veículos Leves sobre Pneus (VP) - Em vias elevadas
Figura 8 - Eixos de Estruturação Transformação Urbana (São, Paulo, 2014)

Esses eixos são definidos nas áreas de influência ao longo dos sistemas de transporte coletivo de média e alta capacidade, como metrô, trem e corredores de ônibus, que têm como princípio o melhor aproveitamento de áreas bem localizadas e próximas à infraestrutura de transporte público. A Figura 9 mostra a estratégia de definição das áreas de influência do transporte público coletivo, compreendida dentro de um raio de 400 a $600 \mathrm{~m}$ de acessos à estação de metrô e trem, e por linhas paralelas com distancias entre 150 e 300 metros dos corredores de ônibus.

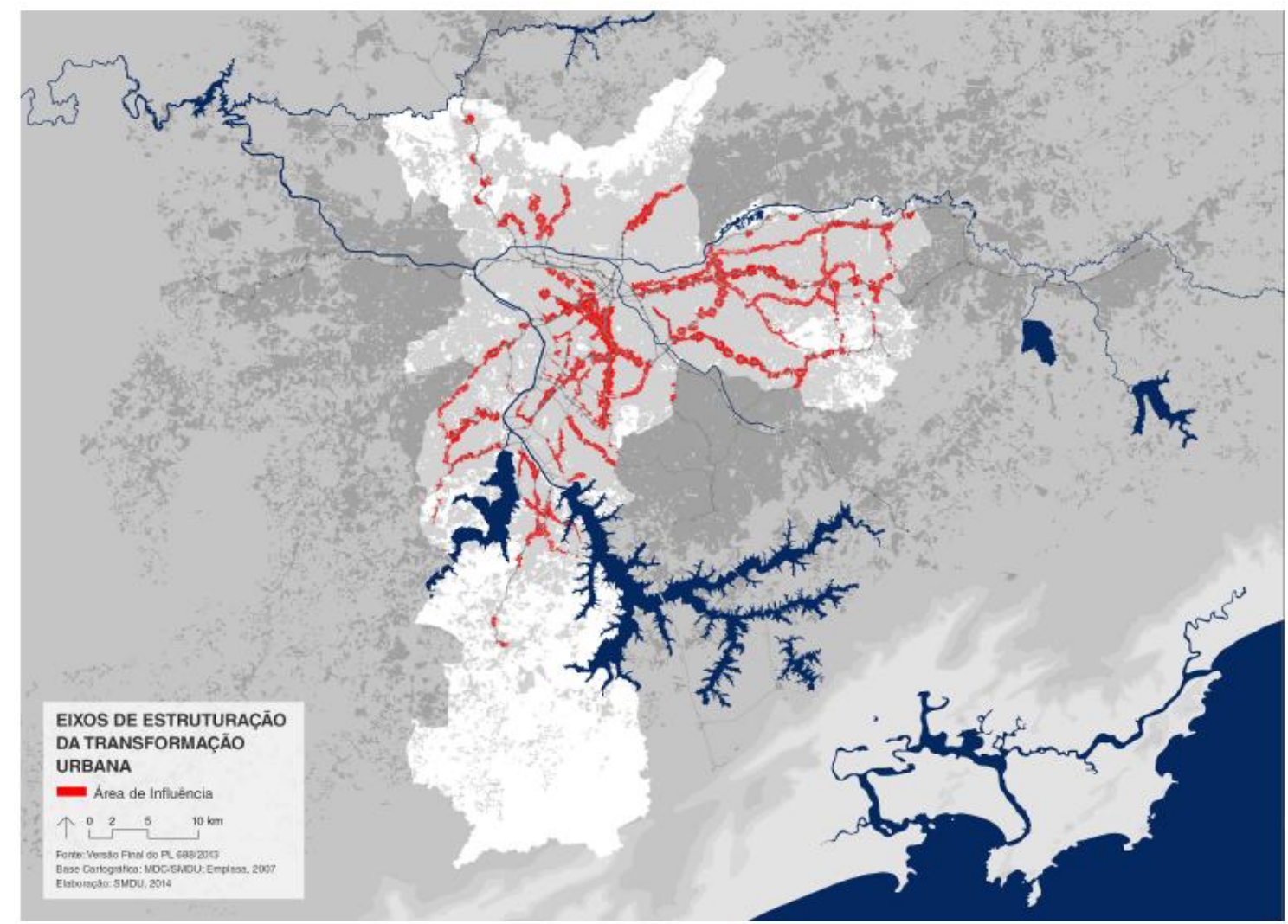

Figura 9 - Delimitação das áreas de influência dos Eixos de Estruturação da Transformação Urbana (SMHDU, 2014) 
As áreas de influências dos Eixos de Estruturação da Transformação Urbana preveem a otimização e humanização destes espaços da cidade, através da ampliação do Coeficiente Máximo de Aproveitamento, da definição da Cota Parte Máxima de Terreno por Unidade, que seria o número mínimo de unidades habitacionais a serem construídas em novos empreendimentos, a implementação do uso misto, de fachadas ativas, de espaço para fruição pública para garantir a qualificação dos espaços públicos por meio de incentivos urbanísticos e fiscais e a delimitação de larguras mínimas para calçadas de no mínimo $5 \mathrm{~m}$ de largura nas imediações dos corredores e pontos de transporte e de $3 \mathrm{~m}$ nas áreas de influência. A limitação da utilização do automóvel também é prevista dentro das novas normas de aprovação para estacionamentos, conforme ilustra a Figura 10.

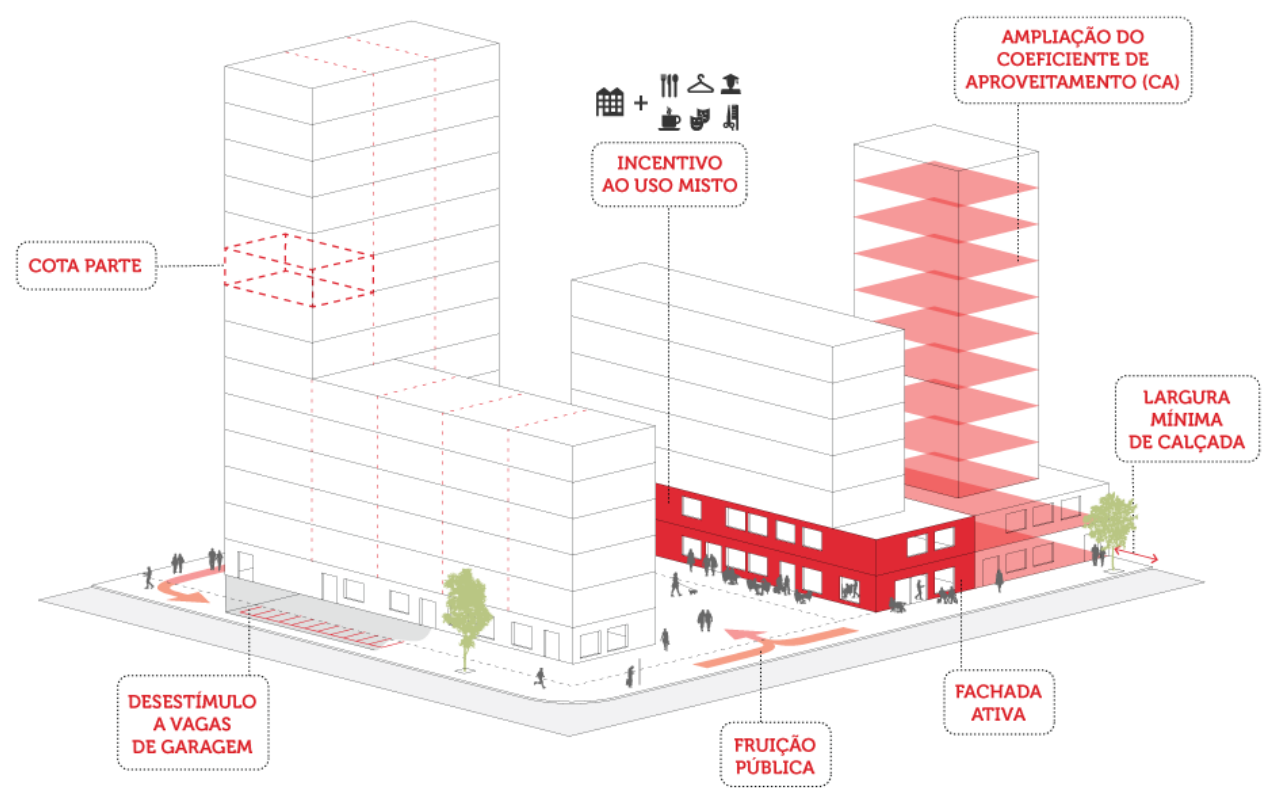

Dentre os parâmetros estabelecidos para incentivar o aumento da densidade populacional, o plano define nas áreas de influência dos Eixos de Estruturação da Transformação Urbana, o Coeficiente Máximo de Aproveitamento igual a 4, e nas demais áreas da cidade Coeficiente Máximo de Aproveitamento igual a 2, tornando-se um dos parâmetros mais importantes para aumentar a concentração da população em áreas que proporcionam um melhor acesso à cidade. Paralelamente, outra estratégia que também viabiliza a adensamento populacional é a implantação de $25 \%$ de Habitação de Mercado Popular e 50\% de Habitação de Interesse Social em empreendimentos situados nos eixos de estruturação. Esses empreendimentos podem ser construídos com um Coeficiente Máximo de Aproveitamento igual a 7, otimizando ainda mais o adensamento desses eixos e garantindo a diversificação socioeconômica nessas áreas.

Medidas para desestimular o uso do transporte individual em áreas bem providas de transporte público é uma medida fundamental e, para isso o PDE-SP rompe com a exigência de número mínimo de vagas por empreendimento na área de influência dos Eixos de Estruturação da Transformação Urbana, como ilustra a Figura 11, impedindo a implantação de vagas para carros em áreas entre o alinhamento dos lotes e das edificações ao nível do passeio público e em áreas cobertas do pavimento de acesso das edificações até o limite de $15 \mathrm{~m}$. Além de romper com o limite mínimo de vagas por empreendimento, o plano define um limite de vagas de estacionamento em áreas públicas em algumas áreas da cidade para controlar as viagens motorizadas, especialmente em áreas próximas aos eixos de transporte público. 


\section{DESINCENTIVO AO AUTOMÓVEL INDIVIDUAL}

Restrição da área considerada não computável de garagens nas Áreas de Influência
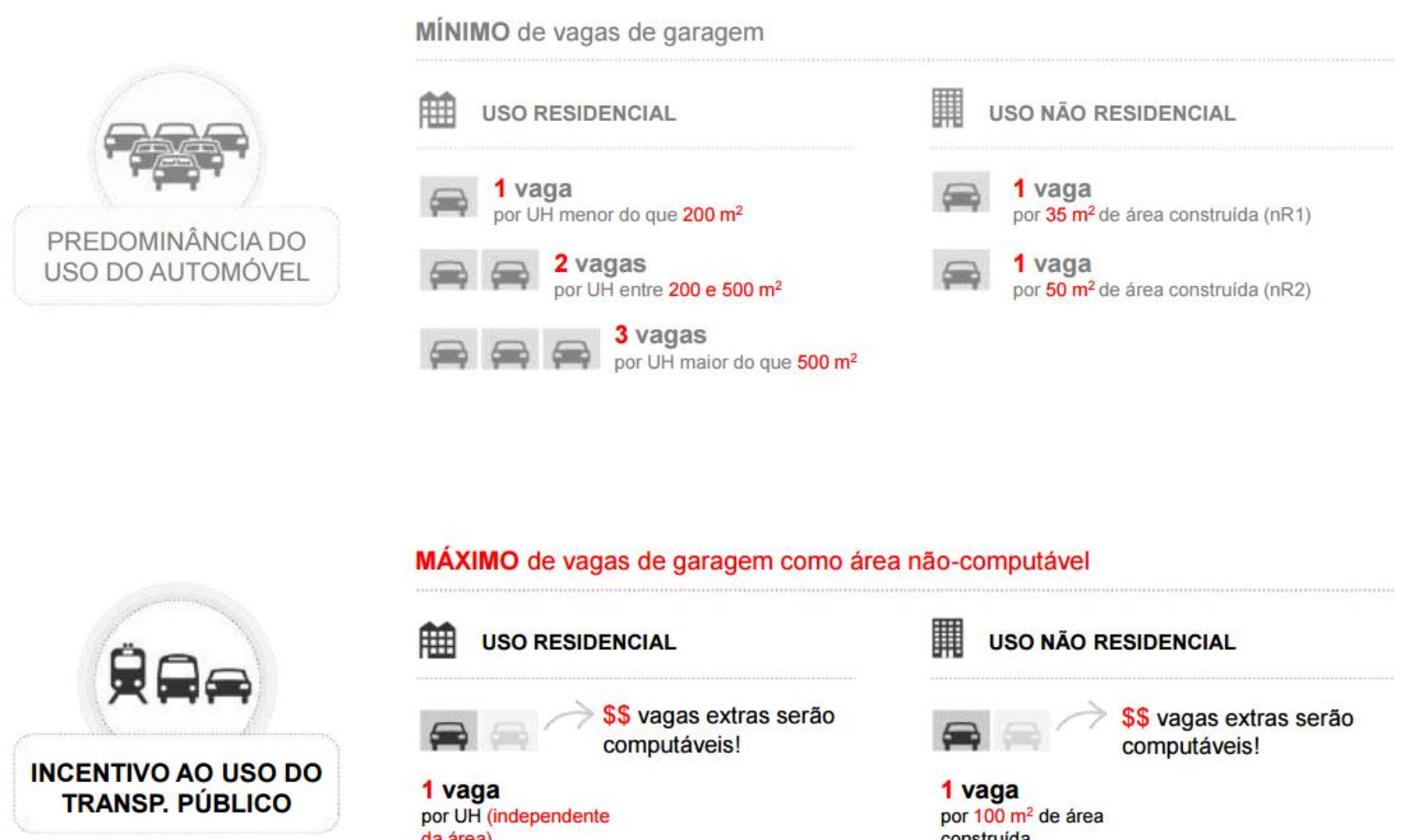

MÁXIMO de vagas de garagem como área não-computável
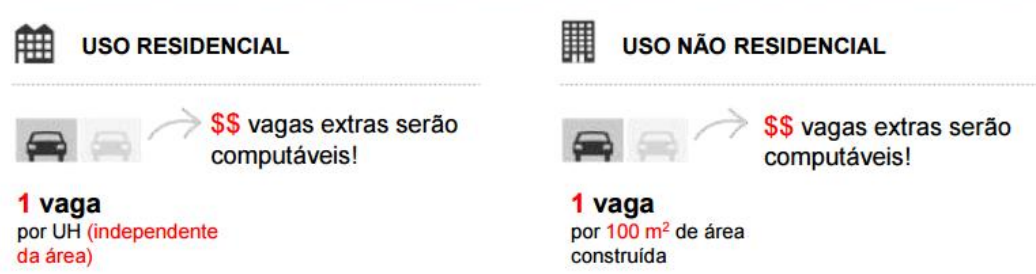

Figura 11 - Estratégias de incentivo ao uso do Transporte Público nos Eixos de Estruturação da Transformação Urbana (São Paulo, 2014)

A imagem anterior nos demonstra que nas edificações residenciais presentes nas áreas de influência serão permitidos apenas uma vaga de garagem por unidade habitacional independente da área da unidade, e uma vaga de garagem para cada $100 \mathrm{~m}^{2}$ de edificações de uso não residencial. Essa estratégia rompe totalmente com a predominância do uso do automóvel individual e se contrapõe com a proposta anterior. Destaca-se ainda que as vagas que excederem esse número serão computadas dentro da área máxima de construção para aquele terreno que deve ficar dentro do coeficiente máximo da região.

Outras medidas para melhoria das condições de mobilidade urbana é a criação do Plano Municipal de Mobilidade Urbana, que possibilita a definição das ações de ampliação, qualificação e integração do sistema de transporte a partir da análise de diagnósticos de forma participativa, além do PDE-SP reconhecer outros meios de transporte inserindo novas formas de deslocamento do Sistema de Mobilidade, tais como logística e cargas, hidroviário e de compartilhamento de automóveis, para estruturação de uma matriz de deslocamentos articulada e eficiente.

O PDE-SP define áreas estratégicas para aplicação de instrumentos de função social da propriedade, disponíveis no Estatuto das Cidades com o intuito de combater a ociosidade de imóveis através da aplicação do Parcelamento, Edificação e Utilização Compulsórios - PEUC, e do Imposto Predial e Territorial Urbano - IPTU progressivo no Tempo. O plano define como áreas estratégicas para aplicação desses instrumentos a área central da cidade e áreas ao longo dos eixos de transporte público.

O plano também prevê o destino de $30 \%$ dos recursos do FUNDURB para HIS - Habitação de Interesse Social a ser construído nas Zonas Especiais de Interesse Social - ZEIS, garantindo o investimento na habitação destinada à população de menor renda. Amplia as ZEIS 1, 3, 4 e 5, sendo as ZEIS 3 e 5 nas áreas centrais e qualificadas da cidade, conforme Figura 12, que são próximas a benfeitorias urbanas e ao longo de eixos de transporte. 


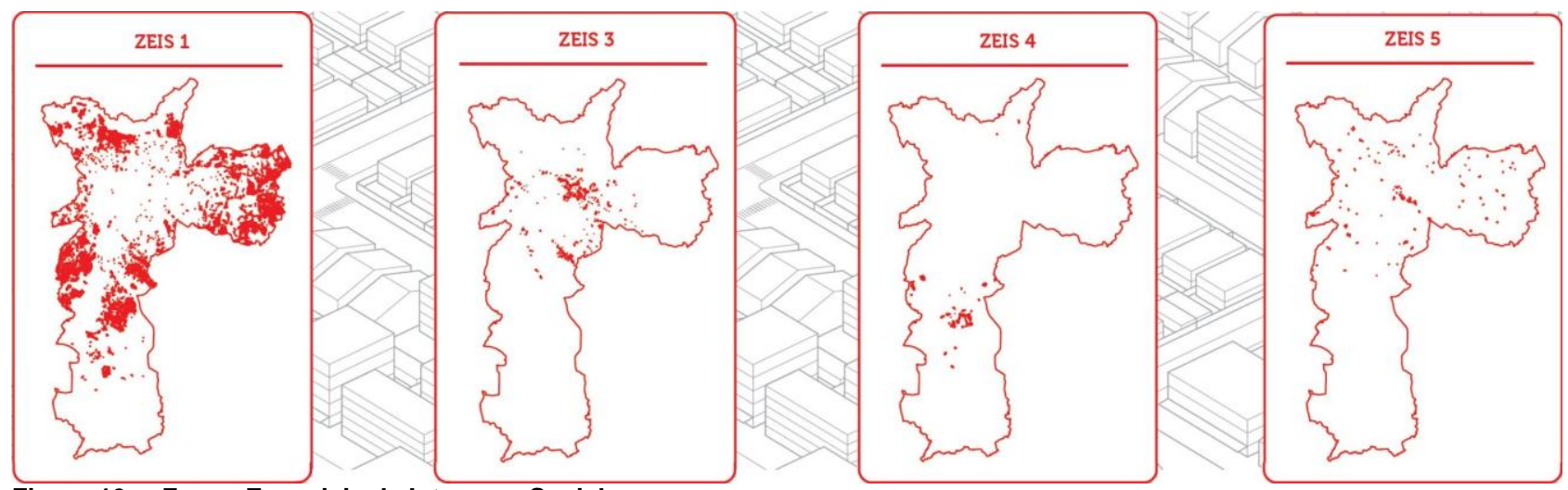

Figura 10 - Zonas Especiais de Interesse Social

(SMHDU, 2014)

Essa estratégia refletirá também na diversificação das áreas de concentração de comércio e serviço bem como em aspectos segregacionista da cidade, visto que a população de menor renda geralmente se concentra nas áreas periféricas, diminuindo então a necessidade de longas viagens para que essa população realize suas atividades diárias, promovendo o acesso aos equipamentos e aos serviços públicos e garantindo assim o direito à cidade às classes de rendas menos abastadas.

Seguindo nesta linha de estratégias, o plano prioriza o atendimento às famílias com rendimento de até três salários mínimos, que representam a maior parte do déficit habitacional, definindo que $60 \%$ da construção das novas habitações sejam para essa faixa. Estabelece uma cota de solidariedade para novos empreendimentos que virão a ser construídos nos Eixos de Estruturação da Transformação Urbana com área construída superior a $20 \mathrm{mil} \mathrm{m}^{2}$, de maneira que $10 \%$ de sua área seja destinada à habitação de interesse social - HIS.

O plano ainda define algumas estratégias para promover o desenvolvimento econômico da cidade. A estruturação de redes de centralidades polares e linear promove um desenvolvimento mais equilibrado na cidade e incentiva o uso residencial associado à implantação de outras atividades para dinamização econômica, como pólos estratégicos para desenvolvimento econômico, parques tecnológicos e áreas industriais) ampliando a oportunidade em diversas áreas da cidade e assim, diminuindo a necessidade de grandes deslocamentos, reduzindo a desigualdade espacial.

\section{CONSIDERAÇÕES}

Considerando a complexidade das políticas públicas urbanas, este estudo teve como propósito contrapor a discussão teórica e articular a leitura do Plano Diretor Estratégico do Município de São Paulo para analisar como os Eixos de Estruturação da Transformação Urbana associados à um conjuntos de estratégias de direito à cidade, têm em suas proposições promover um desenvolvimento urbano mais igualitário na maior cidade da América Latina.

A perversa combinação das distâncias entre oferta e vulnerabilidade que a cidade de São Paulo acumulou pelo seu processo de expansão desordenado, fragmentado e segregado impediu que todos os cidadãos paulistanos fossem beneficiados pelas oportunidades de trabalho, lazer e cultura. A maior fragilidade encontrada no tratamento nas questões de mobilidade urbana nas políticas públicas foi o tratamento como uma questão de provisão de serviços de transporte, sem articulação com o uso e a ocupação do solo, se resumindo basicamente como planos viários e de transporte público.

O presente artigo, portanto, apontou a abordagem do planejamento urbano integrado à mobilidade urbana para promover o direito à cidade à todos os cidadãos de São Paulo. Os Eixos de Estruturação da Transformação Urbana ganha destaque não apenas pela ampliação do sistema de transporte públicos, mas também pela redução das distâncias entre origens e destinos ao incentivar o adensamentos populacional em seus eixos de influência, especialmente ao definir estratégias para inserção da população, especialmente a de menor renda, o que reforça ainda mais a intenção de diminuir as distâncias sociais no âmbito do direito à cidade. 
O Plano Diretor Estratégico de São Paulo foi elaborado a partir de um processo participativo e define um conjunto de estratégias para ordenar o desenvolvimento urbano com ênfase nas questões de mobilidade e acessibilidade mas, cabe destacar que as desigualdades socioespaciais e o direito à cidade para poucos é decorrente de um longo período de descontrole no processo de expansão da cidade de São Paulo. A centralização dos equipamentos públicos e das oportunidades versus a periferização da população de menor renda com baixo padrão de mobilidade são características já consolidadas, sendo assim, um desafio para o poder público municipal tendo em vista que rompem com um padrão já consolidado.

Importante ressaltar que quanto menor a renda e maior a distância das famílias das áreas de concentração de ofertas de emprego e de serviços público, mais dependente do transporte coletivo se tornam essas famílias. Portanto, garantir o direito à mobilidade urbana é uma forma de reduzir a exclusão social e promover o direito à cidade, visto a interferência que as condições de deslocamento têm em relação a esses aspectos e na qualidade de vida dessa população.

A mobilidade urbana, mesmo sendo um tema importante na discussão de cidades, não ganhava destaque na definição de políticas públicas urbanas de forma tão direta. Para tanto, essa temática torna-se importante na cidade de São Paulo por sua expressão em processos de segregação socioespacial, no sentido de reverter em um espaço urbano com disparidades menos intensas. Contudo, para que as estratégias definidas no atual Plano Diretor de São Paulo sejam de fato aplicadas e efetivadas, será necessário inverter a lógica mercantil do transporte coletivo que visa, atualmente, uma maior agilidade do lucro em detrimento de direitos que já são garantidos pela Constituição Federal de 1988, como trabalho, moradia, saúde, educação, e lazer e sua distribuição equilibrada poderia promover o direito à cidade.

\section{BIBLIOGRÁFIA}

BALBIM, R. (2015). Mobilidade: uma abordagem sistêmica. Em BALBIM, R., KRAUSE, C., LINKE, C.C. Cidade e movimento: Mobilidades e interações no desenvolvimento urbano (23-42). Brasil: Governo Federal.

BARBOSA J.L. (2016). O significado da mobilidade na construção democrática da cidade. Em BALBIM, R., KRAUSE, C., LINKE, C.C. Cidade e movimento: Mobilidades e interações no desenvolvimento urbano (43-56). Brasil: Governo Federal.

BONDUKI, N. (2011). O modelo de desenvolvimento urbano de São Paulo precisa ser revertido. Estudos avançados, 25(71), 23-36.

CALDEIRA, Teresa Pires Rio. Cidade de muros: crime, segregação e cidadania em São Paulo. São Paulo: Edusp, 2000, $400 \mathrm{p}$.

Caderno De Formação: Direito À Cidade (2015). Prefeitura de São Paulo, direitos humanos e cidadania. São Paulo.

Constituição da República Federativa do Brasil (1988). Camara dos deputados. Brasil.

GREEN A.E., OWEN D. (2006). The Geography of poor skills and access to work. Joseph rowntree foundation: York. https://www.jrf.org.uk/report/geography-poor-skills-and-access-work (Consulta: 0 2/05/2017)

HODGSON F.C., TURNER J. (2004). Participation not consumption: the need for new participatory practices to address transport and social exclusion. Transport Policy. Elsevier: Oxford, UK. 265272. http://worldcat.org/oclc/29485010 (Consulta: 02/05/2017)

Lei no 10.257 artigos 182 e 183 (Estatuto da Cidade), (2001). Constituição Federal. Brasil.

Lei no 12.587 (2012).Constituição Federal. Brasil.

Lei oㅜ 16.050 (2014). Constituição Federal. Brasil.

LUCAS, K., GROSVENOR, T., SIMPSON, R. (2001) Transport, the environment and social exclusion. York Publishing Services Limited: York-UK

MARICATO, E. (2001). Brasil, cidades: alternativas para a crise urbana. Petrópolis: Vozes.

MILLER H. (2007) Place-based versus people-based geographic information science. Geography Compass 1: 2: 503-535. http://idwebhost-202-

147.ethz.ch/Courses/geog231/Miller_PlaceBasedVsPeopleBasedGIS_GeographyCompass07@200709-12T17\%3B22\%3B04.pdf (Consulta: 02/05/2017)

NAKANO, K. (2015). A crise da mobilidade urbana na Região Metropolitana de São Paulo.Em:BÓGUS, L.M.M., PASTERNAK, S. São Paulo: transformações na ordem urbana. (263-295). Rio de Janeiro: Letra Capital. 
NAKANO, K.,CAMPOS C.M., ROLNIK R. (2004). Dinâmicas dos subespaços da área central de São Paulo. SOMEKH, N., COMIN, A.A. Caminhos para o centro: estratégias de desenvolvimento para a região central de São Paulo (123-158). São Paulo: EMURB.

NEGRI, S. M. (2008). Segregação Sócio-Espacial: Alguns Conceitos e Análises. En Coletâneas do nosso tempo v. VII, n8 (129-153). Rondonópolis

Plano Diretor Estratégico do Município de São Paulo 2002 - 2012 (2004). Secretaria Municipal de Planejamento Urbano do Município de São Paulo. São Paulo

ROLNIK, R., CYMBALISTA, R.; NAKANO, K. (2011). Solo urbano e habitação de interesse social: a questão fundiária na política habitacional e urbana do país.Revista de Direito - ADVOCEF (Porto Alegre),13(1), 123-158.

SABATINI, F.; SIERRALTA, C. (2006) Medição da segregação residencial: meandros teóricos e metodológicos e especificidade latino-americana. En CUNHA, J.M.P. (Org.). No-vas metrópoles paulistas: população, vulnerabilidade e segregação. Campinas: Nepo/Unicamp (169-195).

SAULE JR., N. \& UZZO, K. (2009). A trajetória da reforma urbana no Brasil. Diálogos, propostas, histórias para uma cidadania mundial, 2009. Disponível em: <http://base.d-p-h.info/pt/fiches/dph/fiche- -dph8583.html >. Acesso em: 3 ago. 2015.

SCARINGELLAA. R.S. (2001). Crise Da Mobilidade Urbana Em São Paulo.Revista São Paulo em Perspectiva. São Paulo, 1(15), 55-59.

SILVA, A.N.R., COSTA, M.S., MACÊDO, M.H. (2016). Planejamento integrado, organização espacial e mobilidade sustentável no contexto de cidades brasileiras. Em BALBIM, R., KRAUSE, C., LINKE, C.C. Cidade e movimento: Mobilidades e interações no desenvolvimento urbano (81-100). Brasil: Governo Federal.

SILVA, S. R. M et al (2015) Mutações nas dinâmicas socioespaciais das periferias urbanas: reflexos na diversidade urbana e na composição social. Revista Cadernos da FAUTL (Faculdade de Arquitectura da Universidade Técnica de Lisboa)

SOMEKH. N. (2000). A cidade que não pode parar: São Paulo em quatro planos. Cinco séculos de cidade no Brasil, 6(3), 1-23.

TORRES, H. G.; MARQUES, E.; FERREIRA, M. P.; BITAR, S. (2003). Pobreza e espaço: padrões de segregação em São Paulo. São Paulo, Estudos Avançados, 17 (47): 1 - 32.

VASCONCELLOS, E.A. (2016). Mobilidade cotidiana, segregação urbana e exclusão. Em BALBIM, R., KRAUSE, C., LINKE, C.C. Cidade e movimento: Mobilidades e interações no desenvolvimento urbano (57-79).Brasil: Governo Federal.

VIGNOLI, J.R. (2008). Movilidad cotidiana, desigualdad social y segregación residencial en cuatro metrópolis de América Latina. EURE Santiago, 34(103), 49-71. https://dx.doi.org/10.4067/S025071612008000300003 (Consulta: 30/04/2017)

VILLAÇA, F. (2011). São Paulo: segregação urbana e desigualdade. Estudos avançados, 25(71), 37-58.

\section{FONTES ELETRONNICAS}

https://www.tomtom.com/en_gb/trafficindex/ (Consulta: 16/02/2017)

http://www.metrocptm.com.br/ (Consulta: 16/02/2017) 